\title{
A sombra do Eu Puro: Merleau-Ponty e o "último" Husserl
}

\author{
The shade of the Pure Ego: Merleau- \\ Ponty and the "last" Husserl
}

\section{Resumo}

Em Le Philosophe et son Ombre, Merleau-Ponty agencia uma lapidar metáfora no intuito de circunscrever certo domínio de experiência, em rigor, pré-reflexiva, que estaria presente, particularmente, nos últimos trabalhos de Husserl: a sombra. Afinal, o que, mais propriamente, teria permanecido à "sombra" do filósofo? Ora, o pathos corolário do saber ocidental: "a tradição como esquecimento das origens". Husserl então entrevê outra tarefa cara à fenomenologia, aquém e além de seu idealismo transcendentalmente professo: o retorno à Lebenswelt como horizonte pré-teorético. Trata-se, arqueologicamente, de escavar uma camada de evidência originária, isto é, um mundo bruto, em estado barroco ou selvagem como ainda não pensado. É essa zona de sombra como emblema concreto do Eu puro que não pode mais ser "posta entre parênteses".

Palavras-chave: Husserl. Redução. Eu Puro. Merleau-Ponty. Sombra.

\begin{abstract}
In Le Philosophe et son Ombre, Merleau-Ponty agencies a lapidary metaphor to circumscribe, strictly, a certain pre-reflexive domain of experience, which would be present in the last works of Husserl: the shadow. After all, what, more properly, would
\end{abstract} a Universidade Estadual do Oeste do Paraná (UNIOESTE), Cascavel, PR, Brasil. Doutor em
Filosofia, e-mail: cafsilva@uol.com.br 
have remained in the "shadow" of the philosopher? The pathos corollary of Western knowledge: "tradition as a forgetting of origins". Husserl then glimpsed another expensive task to phenomenology, short and beyond his transcendentally professed idealism: the return to Lebenswelt as a pre-theoretical horizon. It is, archaeologically, to excavate a layer of original evidence, that is, a crude world, barbaric or savage as not yet though. It is this zone of shadow as the concrete emblem of the pure Ego that can no longer be "put in parentheses".

Keywords: Husserl. Reduction. Pure Ego. Merleau-Ponty. Shadow.

"Se você esconde minha sombra na sua, a minha continua existindo, porque, se você se afasta, eu a vejo" (Carlota, 9 anos)

Dê também sentido ao seu dito: dê-lhe a sombra (Paul Celan)

\section{Introdução}

A metáfora da sombra se revela significativamente sugestiva a Merleau-Ponty no momento em que o filósofo busca circunscrever o estatuto de certa ordem de experiência, em rigor, pré-reflexiva que se transfiguraria cada vez mais nos últimos trabalhos de Husserl. Trata-se de interrogar a experiência do impensado, ou seja, aquilo que remonta às origens mesmas da reflexão como potência interrogativa. Ora, é essa alusão sui generis que encontramos lapidarmente no célebre ensaio Le Philosophe et son Ombre. Mais que um simples gesto de homenagem, o texto assume, a bem da verdade, um viés programático da própria incursão fenomenológicoontológica merleau-pontyana para além do idealismo husserliano transcendentalmente professo. Merleau-Ponty vê em Husserl uma experiência de pensamento que não se descola, por assim dizer, daquilo que a anuncia subrepticiamente como inteligibilidade nascente. É esse movimento geral que buscaremos reconstituir no sentido de demarcar a própria zona de sombra que circunda, de forma inalienável, o Eu Puro e suas operações. 


\section{A sombra do Eu puro}

Antes, porém, de restituir o sentido e alcance fenomenológico da metáfora da sombra no curso da nouvelle ontologie de Merleau-Ponty e sua respectiva retomada de Le Philosophe et son Ombre, cabe observar o papel desempenhado por essa figura de linguagem na história do pensamento no Ocidente. Sua função exerce certo caráter paradoxal: a sombra se define pelo contraste com a luz. Platão, por exemplo, imortalizou tal paradoxo no sétimo livro da República mediante a alegoria da caverna. "A verdade vista pelo prisioneiro da caverna" - como comenta Merleau-Ponty (1945, p. 52) - “que prefere as sombras às quais está acostumado sem, no entanto, compreender que elas derivam da luz", se torna uma espécie de pedra fundamental da tradição filosófica ao marcar um território próprio especulativo. O que a sombra produz é, de fato, uma imagem, um simulacro, uma silhueta cuja natureza se caracteriza como errática, imperfeita, finita. A sombra desvela certo éthos, certa forma de vida humana errante, não passando, pois, de uma penumbra, um mero arranjo estético. Ela pertence à ordem do sensível em franca oposição ao inteligível como, aliás, mais tarde, Descartes sacramentaria em seu dualismo a título de um saber não evidente. Tudo se passa como se as sombras fossem más companhias, provocando, à primeira vista, mais desconfiança que qualquer crédito epistêmico ou metafísico.

Não obstante, algumas leituras contemporâneas vêm precisamente desfazer certo equívoco, isto é, restituir à imagem da sombra um papel mais ativo e, por isso mesmo, decisivo. É o que Casati (2001, p. 9) em seu instigante livro, A Descoberta da Sombra, nota simplesmente ao escrever que "luz demais pode fazer mal". Quer dizer, é "a sombra da Terra que revela a verdadeira natureza da Lua" (Ibidem). Foi com a ajuda das sombras que se tornou possível determinar a forma e a dimensão da Terra, estudar a causa dos eclipses, estabelecer as distâncias entre Terra, Lua e Sol. Observando as sombras, o homem conseguiu determinar a latitude de um lugar, constatando ainda que Saturno é circundado por anéis extraordinários e que a Lua viaja a uma velocidade finita (CASATI, 2001). É assim que se reportando aos trabalhos de Piaget, Merleau-Ponty (1945, p. 353) retrata que 
a criança percebe a luminosidade como uma linha de força que atravessa o campo visual, e é por isso que a sombra que lhe corresponde atrás dos objetos é imediatamente posta em uma relação viva com a iluminação: a criança diz que a sombra "foge da luz".

Da mesma forma, do ponto de vista da percepção, volta a ilustrar MerleauPonty (1945, p. 10), “a mancha vermelha que vejo no tapete só é vermelha quando eu levo em conta uma sombra que a atravessa, sua qualidade só aparece em relação com os jogos da luz e, portanto, como elemento de uma configuração espacial”. Esses poucos exemplos já são o bastante a fim de reconfigurar outro olhar acerca desse curioso fenômeno, como se sabe, tradicionalmente associado à escuridão, à simulação.

Ora, na percepção, descreve Merleau-Ponty, o elemento da opacidade é originariamente constitutivo de nossa experiência do mundo. A obscuridade é um fenômeno que "atinge todo o mundo percebido" (1945, p. 232). Há um mínimo de sombra necessária presente no mundo, isto é, certa espessura umbrífera entremeada na vivência humana de forma inexorável. É, portanto, esse aspecto inalienável do acontecimento perceptivo que passa a receber um estatuto proeminente no curso das análises de Merleau-Ponty a ponto de conferir, nos textos de vários autores que lê, uma atenção digna àquilo que, no interior desses escritos, sobrevém de interdito, subentendido, indizível, irrefletido. Nesse contexto, o caso Husserl se torna realmente muito peculiar, paradigmático, por excelência. Le Philosophe et son Ombre é bem mais que um tributo ao insigne mestre. É, de longo alcance, uma releitura que não se pretende restritivamente exegética. Esta, de certo modo, recria Husserl, retomando e acompanhando os seus passos rumo a uma direção que ele próprio tinha em vista, mas que não percorrera a contento ou que, ao menos, deixara em aberto. Afinal, que Husserl é esse que sobrevém no labor dos últimos manuscritos? Tratar-se-ia de um pensador absolutamente seguro em sua tarefa sem qualquer hesitação ou embaraço? A fenomenologia que margeia sua obra está por definitivamente dada e acabada? É um corpo doutrinário rigidamente fechado?

Convém, em primeiro lugar, atermos que a fenomenologia é um destino, ou se quiser, uma espécie de destino sisífico cujo trabalho assume mais o caráter de uma tarefa infinita, incessante, necessitando, pois, de ser constantemente retomada. 
Era, enfim, com esse olhar que Husserl concebia o labor de sua obra; uma obra cujo curso é acompanhado sempre por uma zona de "sombra" e, por isso, sempre incompleta, inacabada, prenhe de paradoxos. Isso se torna cada vez mais visível quando atentamente, guiados sob as mãos de Merleau-Ponty, reconstituímos as "pegadas" do que se convencionou chamar de "último Husserl". Assim, a fenomenologia husserliana em seus derradeiros capítulos passa a revelar um traço marcante, por vezes, não entrevisto: o de que a razão toma corpo com o seu próprio avesso, a desrazão. O que Husserl desvela é uma dobra secreta entre a reflexão e a irreflexão. Há um jogo de luz e sombra em perpétuo movimento. A sombra já não é mais o que se opõe à luz; não é negação da luz natural, mas, sorrateiramente, sua cara metade. Essa dobra, essa Gestalt é como Janus, tem uma dupla face, consanguineamente gêmea.

A fim de melhor reconstituir esse duplo perfil, isto é, tal dialética do visível e do invisível, Merleau-Ponty diagnostica, a partir do "último" Husserl, o pathos corolário do saber ocidental: “a tradição como esquecimento das origens” (1960, p. 201). Não se trata, aqui, como acertadamente chama a atenção Heidegger ${ }^{1}$ de um retorno "psicológico". O esquecimento, em sentido originário, é o pano de fundo do pensamento, ou seja, seu avesso, aquilo que, de certo modo, permanecera em estado bruto, selvagem cuja destinação se inscreve na história mesma do Ocidente. A tarefa da fenomenologia não será outro senão a de circunscrever essa zona um tanto obscura, opaca do que fora até então pensado, a saber, seu impensado. Por isso, o fenomenólogo opera como um arqueólogo: ele chama, para si, a missão de explorar, de escavar um domínio para pensar que, portanto, ainda não foi pensado. É o que atesta Heidegger (1997, p. 105):

\footnotetext{
1 Heidegger aborda o tema do "esquecimento" num sentido antipsicológico: "Num tal velar consiste, entretanto, a essência do esquecimento experimentada pelos gregos. $O$ esquecimento não é, no fim, isto é, desde o começo de sua essência, nada de negativo. Mas, enquanto velamento é ele presumivelmente um abrigar que conserva o que ainda não chegou ao desvelamento [...]. O 'esquecimento do ser' foi, muitas vezes, representado como se o ser fosse, para expressá-lo numa imagem, o guarda-chuva que a distração de um professor de filosofia esqueceu em algum canto [...]. Ora, o esquecimento pertence à tarefa do próprio ser, impera como destino de sua essência" (HEIDEGGER, 1969, p. 50).
} 
Quando se trata do pensar, quanto maior for a obra feita - o que absolutamente não coincide com a extensão e a quantidade dos escritos -, mais rico será, nessa obra, o impensado, ou seja, aquilo que, através dessa obra e apenas por ela, volta-se para nós como o-jamais-ainda-pensado ${ }^{2}$.

O que, nesse momento, se torna matéria-prima de interesse para MerleauPonty, é o acompanhamento da experiência mais genuína do pensamento, isto é, o nascimento contínuo de um pensar que certa exegese mascara, por vezes, ao cristalizar um certo Husserl "transcendental" instalando-o solenemente na história da filosofia. Que Husserl, enfim, seria esse?

Tomemos o tema da redução fenomenológica. Ora, sabe-se sobre o quanto, incansáveis vezes, Husserl se debruçara acerca do teor dessa questão a ponto de reconhecer nela o índice de um incontornável enigma. Não se trata, obviamente, de que ele não teria conseguido assegurar as bases da fenomenologia ou até mesmo de chegar a se enganar a respeito daquilo que buscava. Não, nada disso! É que, para o filósofo, os problemas da redução não constituem um prefácio, mas o começo da pesquisa ou ainda, num certo sentido, o todo da investigação já que remete à uma tarefa ou meditação infinita, prestes sempre por recomeçar. É com "Husserl” avista Merleau-Ponty (1960, p. 204) — que se "redescobre essa identidade do 'entrar em si' e do 'sair de si' que, para Hegel, definia o absoluto". É que Husserl reconfigura, radicalmente, o estatuto da reflexão à luz de uma redefinição da subjetividade. O eu puro, nessa investida, se torna o reduto último irredutível dessa operação, a fonte doadora de sentido. Por isso, o filósofo jamais abdica, é claro, dessa posição ou atitude. Ora, Merleau-Ponty retoma justo esse princípio corolário, em sua gratuidade fenomenológica, mas realocando noutra perspectiva ou chave de leitura. Um novo campo transcendental é então aberto, anuncia ele: "não é preciso tratar o Eu transcendental como o verdadeiro sujeito e o eu empírico como sua sombra ou seu rastro" (MERLEAU-PONTY, 1945, p. 487-488). O trabalho da

2 "O impensado não é o que não foi pensado, nem o que tendo sido pensado não soube ser dito, nem muito menos o que teria sido pensado e não pôde ser proferido. Não é o 'menos'; é o excesso do que se quer dizer e pensar sobre o que se diz e se pensa [...]. $O$ impensado não é o que estaria ausente como privação, mas aquilo cuja ausência é promessa e antecipação. Como todo invisível, o impensado é uma ausência que conta no mundo porque não é um vazio, mas ponto de passagem. Não é buraco. É poro. Não é lacuna que preenchemos, mas trilha que seguimos" (CHAUÍ, 2002, p. 39; 40). 
reflexão pressupõe, ao fim e ao cabo, um fundo irrefletido que não emana, exclusivamente, de um eu depurado de toda sensibilidade. Afinal, será preciso ver que já em Idéias (I), Husserl, ao menos, compreendera que

[...] refletir é revelar um irrefletido que está à distância [...] não é o irrefletido que contesta a reflexão, mas a própria reflexão que se contesta a si mesma porque seu esforço de retomada, de posse, de interiorização ou de imanência não tem por definição o sentido frente a um termo já dado, e que se retira em sua transcendência sob o próprio olhar mesmo que vai buscá-lo ali (MERLEAU-PONTY, 1960, p. 204).

Isso posto, assevera Merleau-Ponty (1996, p. 55-56), "reencontramos o irrefletido, mas o irrefletido ao qual voltamos não é o que antecede a filosofia ou que antecede a reflexão; é o irrefletido compreendido e conquistado pela reflexão". Desse modo, não é por acaso, ou por ingenuidade que Husserl reconhece aspectos contraditórios em sua própria teoria da constituição, ou seja, na tese da redução. $\mathrm{Na}$ verdade, o que é dito por ele é também imposto por certa situação de fato, qual seja, a facticidade nua e crua. Quer dizer, à medida que "a redução ultrapassa a atitude natural, Husserl logo acrescenta que essa ultrapassagem conserva inteiro o mundo da atitude natural"” (1960, p. 205). Eis porque,

Desde as Idées (II) parece claro que a reflexão não nos instala num meio fechado e transparente, não nos faz passar, pelo menos imediatamente, do "objetivo" para o "subjetivo", mas tem antes por função desvelar uma terceira dimensão em que essa distinção torna-se problemática. (MERLEAU-PONTY, 1960, p. 205) ${ }^{3}$.

Pois bem: é essa "terceira dimensão" que agora entra em jogo. MerleauPonty passa a explorá-la fenomenologicamente como uma espécie de "região selvagem", uma camada em estado bruto que permanecera "esquecida", intacta, abaixo do edifício da cultura e do saber, ou se quiser, prévia à reflexão, que não fora, pois, colonizada pelo pensamento. É essa camada mais profunda que o fenomenólogo, como bom "arqueólogo", cumpre escavar ou trazer à tona. Ao

${ }^{3}$ Ao parafrasear as Idées (II), Merleau-Ponty afirma que, "num sentido, toda reflexão é incapaz de apreender o irrefletido, porque ela não é mais o irrefletido. Ele faz desta dificuldade uma resposta: o fato, a situação filosófica inicial é que reflito sobre algo que é prévio à reflexão, mas só tenho noção deste irrefletido, através do movimento pelo qual tento retomar e refletir" (MERLEAU-PONTY, 2000, p. 333). 
orientar-se por essa "terceira via", Husserl parece cada vez mais, admite MerleauPonty, conferir cidadania à Weltthesis, isto é, reconhecendo nessa um certo grau de evidência. Trata-se do irrefletido como uma zona de sombra que recobre a razão, a reflexão. Daí explica-se o retorno à Lebenswelt na La Crise des Sciences Européennes (2004) como horizonte último, entrevisto como experiência pré-teorética. Obviamente, não se trata mais do mundo de Galileu ou da Terra de Copérnico, mas do mundo da vida como Terra Originária, Natureza Primordial (SILVA, 2019, 2012). É, pois, esse horizonte que se vislumbra ou se insurge acima como "terceira dimensão", quer dizer, como o pano de fundo entreaberto cujas frestas, passa-se um pouco de luz. Como poetiza René Char (1983, p. 411), "só podemos viver no entreaberto, exatamente sobre a linha hermética de partilha da sombra e da luz". Ora, a nova "luz natural", o Eu Puro e suas operações circunscrevem-se nessa inalienável zona de sombra. Aquém da transparência da razão, reside sempre uma auréola de sombra que dirige oblíquo e lateralmente o trabalho paciente do conceito. O fenomenólogo se vê então obrigado a descer, de uma vez por todas, a esse domínio, a esse lusco-fusco da doxa. Há um impensado a pensar. É bem verdade, contudo, assenta Merleau-Ponty, que Husserl nunca se explicou bastante a esse respeito. O que encontramos sugestivamente em seus últimos escritos, são índices, pontos de apoio que parecem gradativamente remeter a certo meio ontológico diverso do em si e do para si.

É, em rigor, perseguindo esse movimento de pensamento que Husserl (2001) concede cidadania a outro tema de suma importância: a intersubjetividade. Sobre isso, Merleau-Ponty (1945, p. vi) lembra que, para a tradição cartesiana,

[...] não há nada de oculto atrás de um rosto ou de um gesto, nenhuma paisagem para mim inacessível, mas apenas um pouco de sombra que só existe pela luz. Para Husserl, ao contrário, sabemos que existe um problema do outro e o alter ego é um paradoxo.

Sendo assim, como melhor poderíamos reconhecer a verdade desse paradoxo? O que o faz tão especial que, aliás, Husserl viria consagrar um lugar de honra na quinta e última das Méditations Cartésiennes (2001)?

Se, ao apertar a mão de outro homem, tenho a evidência de seu ser-aí, é porque ela se coloca no lugar de minha mão esquerda: meu corpo se anexa ao corpo do outro nesta "espécie de reflexão" da qual ele é paradoxalmente a sede. Minhas duas mãos são "co-presentes" ou "coexistem" 
porque são as mãos de um só corpo: o outro aparece por extensão dessa co-presença. Ele e eu somos como os órgãos de uma só intercorporeidade (MERLEAU-PONTY, 1960, p. 212-213).

Ora, "na verdade, como Husserl o mostra nas Meditações Cartesianas, outrem não é mais que a sombra de mim mesmo" (MERLEAU-PONTY, 2013, p. 233). O fenômeno da co-presença ou coexistência de outrem via a experiência da intercorporeidade como sombra é, no fundo, a amplificação de outro enigma ou paradoxo fundamental:

O enigma é que meu corpo é, simultaneamente, vidente e visível. Ele que olha todas as coisas, também pode se olhar e reconhecer naquilo que vê o "outro lado" de sua potência vidente. Ele se vê vendo, toca-se tocando, é visível e sensível para si mesmo. Ele é um si não por transparência como o pensamento que só pode pensar assimilando o pensado, constituindo-o, transformandoo em pensamento. É, porém, um si por confusão, narcisismo, inerência daquele que vê naquilo que vê, daquele que toca naquilo que toca, do senciente ao sentido. É, portanto, um si tomado entre as coisas, o qual possui uma face e um dorso, um passado e um porvir [...]. Visível e móvel, meu corpo conta-se entre as coisas, é uma delas, preso no tecido do mundo e dotado da coesão de uma coisa. Assim, porque vê e se move, mantém as coisas circulando ao seu redor, pois elas constituem um anexo ou um prolongamento dele mesmo, estão incrustadas em sua carne, fazendo parte de sua definição plena, já que o mundo é feito do mesmo forro que o corpo (MERLEAU-PONTY, 1985, p. 18-19).

Vidente e visível, táctil e tateante, senciente e sensível, o corpo radica essa dublagem, essa dobra secreta, enigmática, por definição. Tal transfiguração ou metamorfose reaparece em toda a sua extensão radical já que primeiramente, há uma

[...] relação de meu corpo consigo mesmo que o transforma no vinculum do eu com as coisas. Quando minha mão direita toca a esquerda, sinto-a como uma "coisa física", mas no mesmo instante, se eu quiser, um acontecimento extraordinário se produz: eis que minha mão esquerda também se põe a sentir a mão direita [...]. Dessa maneira, porque eu me toco tocando, meu corpo efetua "uma espécie de reflexão". Nele e por ele não há somente relação em sentido único daquele que sente com aquilo que ele sente. A relação se inverte: a mão tocada torna-se tocante, de modo que sou obrigado a dizer que o tato aqui está espalhado pelo corpo, que o corpo é "coisa senciente", "sujeito-objeto" (1960, p. 210).

O que tais exemplos, novamente, sugerem? Eles acenam para uma ordem de experiência mais ampla, isto é, mais vasta capaz de comportar todas as dimensões: o sensível como um domínio de presença originária comum. Não se trata do sensível definido em termos clássicos como matéria, empiria, mas como camada de sensibilidade originária, primordial. $O$ sensível também transfigura um prolongamento irradiando-se num meio mais alargado. Como escreve Merleau- 
Ponty (1960, p. 217), é nessa segunda acepção que "Husserl redescobre o sensível como forma universal do ser bruto". Ele simplesmente "escava um mundo mais original" (MERLEAU-PONTY, 2000, p. 219), entrevisto como um "mundo selvagem e um espírito selvagem" (MERLEAU-PONTY, 1960, p. 228). Trata-se, uma vez mais, da Natureza, da Terra (HUSSERL, 1989) em seu sentido primeiro e originário do termo (HUSSERL, 1982, p. 230). Sob esse pretexto, Merleau-Ponty ressignifica a fórmula husserliana do Logos do mundo estético (Logos der ästhetischen Welt) (HUSSERL, 1992, p. 297) como expressão de "nossa proto-história de seres carnais co-presentes num único mundo" (MERLEAU-PONTY, 1960, p. 227).

Vejamos que essa maneira de Merleau-Ponty reler Husserl reorienta, radicalmente, o estatuto da própria questão transcendental noutras bases. É o que desde a Phénoménologie de la Perception não pairava nenhuma sombra de dúvida:

\begin{abstract}
Com o mundo natural e o mundo social, nós descobrimos o verdadeiro transcendental, que não é o conjunto das operações constitutivas pelas quais um mundo transparente, sem sombras e sem opacidade se exporia diante de um espectador imparcial, mas a vida ambígua em que se faz a origem (Ursprung) das transcendências, que, por uma contradição fundamental, me põe em comunicação com elas e, sobre este fundo, torna possível o conhecimento (MERLEAU-PONTY, 1945, p. 418-419).
\end{abstract}

É nesse exato sentido que se pode afirmar que Husserl "entrevê pelo menos, atrás da gênese transcendental, um mundo onde tudo é simultâneo" (MERLEAUPONTY, 1960, p. 226); mundo esse abarcado por uma zona de sombra, de fato, incontornável. Tal circunscrição é a própria experiência:

\begin{abstract}
Husserl invoca a experiência como fundamento último de direito. Eis a ideia: visto que estamos na junção da Natureza, do corpo, da alma e da consciência filosófica, visto que a vivemos, não podemos conceber um problema cuja solução não esteja esboçada em nós e no espetáculo do mundo; deve haver, pois, neles, um meio para compor em nosso pensamento o que vem em bloco em nossa vida (MERLEAU-PONTY, 1960, p. 223-224).
\end{abstract}

Husserl agenda, como tema programático, uma "teoria da experiência antepredicativa" (HUSSERL, 2000, p. 30), na qual se desvelaria "um mundo prévio a toda atividade de juízo” (Idem, op. cit., \$7, p. 35). Trata-se da experiência de um saber latente, um "pré-saber", enquanto "retorno ao mundo da experiência como retorno ao "mundo-da-vida"' (HUSSERL, 2000, p. 53). Essa "penetração na camada 
mais profunda, a camada última originária da experiência antepredicativa, significa uma legitimação da doxa" (Ibidem), que, de modo algum, é um domínio de menor dignidade ao da ciência. A doxa prefigura o domínio "de uma análise originária e de uma fundação subjetiva, da lógica formal tradicional” (HUSSERL, 2000, p. 60). Assim, se torna possível a radicalização de uma "experiência da ipseidade" (HUSSERL, 2000, p. 424), experiência dada “em carne e osso" (leibhaft).

Uma vez chegado a esse ponto, precisa Merleau-Ponty (1960, p. 224), “o campo transcendental deixou de ser somente o de nossos pensamentos para tornarse o da experiência inteira". Com isso, "projeto de posse intelectual do mundo, a constituição torna-se cada vez mais, à medida que amadurece o pensamento de Husserl, o meio para revelar um avesso das coisas que não constituímos” (1960, p. 227$)^{4}$.

É em direção a esse horizonte último que a metáfora da sombra se reveste bem mais que um mero arranjo ou recurso literário. Ela se revela como um fenômeno constitutivo uma vez escavado rente ao trabalho do pensamento.

\section{A sombra como fenômeno}

A sombra se desvela, agora, como o emblema concreto do Eu puro já que constitui o rastro indelével de todo pensador. A sombra é a dimensão inalienável que o filósofo transporta consigo, sendo por ela implacavelmente perseguido. Ela é o avesso ou a contrapartida da reflexão. Não é a ausência de luz, mas “espírito

\footnotetext{
4 "À medida que Husserl passa à execução de seu programa, ele traz à luz os fragmentos de ser que desconcertam sua problemática: nem o corpo que é 'sujeito-objeto', nem a passagem do tempo interior, que não é um sistema de atos de consciência, nem o outro, que nasce por elevação sobre mim ou pela expansão de $\mathrm{mim}$, como Eva nasce de uma costela de Adão, nem a história, que é minha vida no outro e a vida do outro em mim, que é por princípio, como o outro, um 'objeto' inexato, não se deixam conduzir sob a correlação da consciência e de seus objetos, da noese e do noema. A filosofia deixa de ser conhecimento exato, olhar puro sobre os objetos puros: ela é, diz Husserl, 'aquilo que se quer' através das gerações de filósofos nas quais ninguém coincide com a 'interioridade intencional' que todos eles invocam e que constituem em conjunto. Toda consciência é consciência de algo ou do mundo, mas esse algo, esse mundo, já não é mais, como parecia ensinar o 'positivismo fenomenológico', um objeto que é o que ele é exatamente ajustado aos atos de consciência. A consciência é agora a 'alma de Heráclito', e o Ser, que está antes em torno que diante dela, é um Ser onírico, por definição oculto. Husserl disse algumas vezes: um 'pré-ser'" (MERLEAU-PONTY, 2000, p. 280-281).
} 
selvagem" como radicalidade última da luz. A sombra é o excesso da razão, a verdade do cogito, situada não atrás, mas ao redor, na coexistência com outrem, atravessando o trabalho de constituição de ponta a ponta. Tal qual a noite, metaforiza Merleau-Ponty (1945, p. 328), "ela (sombra) me envolve, penetra por todos os sentidos, sufoca minhas recordações, quase apaga minha identidade pessoal". A sombra se transfigura como a noite suprema na qual as ideias, tais como as estrelas, cintilam seu brilho característico. Talvez não tenha sido casual, aliás, sobre o quanto Van Gogh deixou se tocar por esse paradoxo ao retratar sua "noite estrelada".

A sombra se projeta, pois, como a textura invisível na qual, pelo mistério da carnalidade, a reflexão irradia sua luz. Em função disso, a sombra não é privação absoluta, mas aquilo cuja ausência é gênese, abertura, promessa, acontecimento. Como uma "bruma de vida anônima", ela passa a assumir inúmeras modulações, matizes, tons, vibrações. A sombra é o que, originariamente, reside em nós numa só coesão de vida:

\begin{abstract}
Assim se precisou o sentido de nossa admiração diante do mundo percebido. Não é a dúvida pirrônica, nem mesmo o apelo a um domínio imanente de pensamento positivo do qual o mundo percebido não seria mais do que a sombra: a sombra está em nós antes de estar fora, colocando em suspenso a evidência do mundo, recorrendo ao nosso pensamento ou a nossa consciência do mundo, as suas operações e as suas teses, por isso, nada encontraríamos que ultrapasse ou apenas iguale ou explique a solidez do mundo sob nossos olhos e a coesão de nossa vida nele (MERLEAU-PONTY, 1964, p. 133).
\end{abstract}

Tal qual a cauda de um cometa, a sombra acompanha o filósofo como anteparo da reflexão; ele a arrasta consigo como um prolongamento dele mesmo. É sob esse prisma que Monzani (2009, p. 13-14, apud SILVA, 2009) bem observa:

De uma maneira ou de outra, a razão não vê tudo. Há uma sombra da razão, ou melhor, uma zona de sombra, e é isso que Merleau-Ponty pretende investigar, ou não se cansa de investigar; no limite, essa zona de sombra revela o caráter inconcluso da reflexão filosófica. Daí porque, entre outras coisas, ele elevou à dignidade filosófica a psicologia infantil, os povos primitivos e a obra de arte. 
Afinal, se há sempre um fundo, um mínimo de sombra necessário para realçar a produção soberana do Eu, é porque, como descreve Merleau-Ponty (1960, p. 225):

Aquilo que em nós resiste à fenomenologia - o ser natural, o princípio "bárbaro" ${ }^{5}$ de que falava Schelling - não pode permanecer fora da fenomenologia e, portanto, deve ter seu lugar nela. A sombra que o filósofo carrega não é, de fato, a simples ausência de uma futura luz. É o que, desde já, diz Husserl: há uma dificuldade muito "excepcional" não só de "apreender", mas "compreender pelo interior", a relação entre o "mundo da Natureza" e o "Mundo do espírito".

O que Merleau-Ponty acaba de conferir é o estatuto fenomenológico à sombra como fenômeno, ser indiviso, emblema do ser concreto, princípio bárbaro, o avesso mesmo da reflexão e do Eu Puro, aquém da redução. A sombra é, decerto, esse ponto de resistência da fenomenologia, dimensão tal que rememora nosso vínculo carnal com as coisas, com o mundo e com outrem.

\section{Conclusão}

À guisa de conclusão, a sombra nos projeta para aquilo que transcende uma obra. A sua significação não se limita a uma extração meramente exegética. É que a obra sempre diz mais; projetando-se além, bem além. No fundo, esse "além” é um “aquém” prefigurando justamente o que subjaz à reflexão, ou seja, aquilo com o qual não haveria luz. Como Merleau-Ponty (1960, p. 202) avista às voltas do filósofo:

Quando Husserl termina sua vida, há um impensado de Husserl, que é muito seu e que, no entanto, abre para uma outra coisa. Pensar não é possuir objetos de pensamentos; é circunscrever, graças a eles, um domínio para pensar que ainda não foi pensado [...]. Se quisermos reencontrar o pensamento e a obra, e se quisermos ser fiéis a eles, só nos resta um caminho: pensar de novo.

O que instiga a "pensar de novo" ou "o que nos dá a pensar" é o que acompanha, sem tréguas, o filósofo. É justo aquilo que intrepidamente o sombreia

5 (SCHELLING, 1949, p. 187). 
como destino irrecusável; destino esse, atesta Merleau-Ponty (1945, p. xvi) que "se confunde com o esforço do pensamento moderno". O filósofo que caminha nas sombras nada tem o que temer. É nelas que a razão habita em todo seu fulgor, ou seja, em sua luz mais fulgurante, radiante. Nas sombras, a luz faz morada porque mantém uma relação familiar, de parentesco, razão pela qual ela deve, pois, sentir-se em casa. É nessa perspectiva que a última obra de Husserl ensaia uma fenomenologia da sombra como fundo irrefletido que atravessa de ponta a ponta toda práxis filosófica ou científica. É esse "fato inaugural" que antevemos no limite de todo idealismo e de todo solipsismo cuja experiência radical não pode mais ser "posta entre parênteses".

\section{Referências}

CASATI, R. A descoberta da sombra. Trad. Eduardo Brandão. São Paulo: Companhia das Letras, 2001.

CHAR, R. Euvres complètes. Paris: Gallimard, 1983.

CHAUÍ, M. Experiência do pensamento: ensaios sobre a obra de Merleau-Ponty. São Paulo: Martins Fontes, 2002. (Coleção Tópicos).

HEIDEGGER, M. Sobre o problema do ser: o caminho do campo. Trad. E. Stein. São Paulo: Duas Cidades, 1969.

HEIDEGGER, M. Der satz vom grund. (B10). Frankfurt am Main: Vittorio Klostermann, 1997.

HUSSERL, E. Formale und transzendentale Logik. Hamburg: Meiner, 1992 (Gesam. Schriften, 7).

HUSSERL, E. Ideias (I) Ideias para uma fenomenologia pura e para uma filosofia fenomenológica: introdução geral à fenomenologia pura. Trad. M. Suzuki. Aparecida: Ideias \& Letras, 2006.

HUSSERL, E. Idées (II) Idées directrices pour une phénoménologie et une philosophie phénoménologiques pures: Recherches phénoménologiques pour la constitution. Trad. E. Escoubas. Paris: PUF, 1982.

HUSSERL, E. La terre ne se ment pas. Trad. D. Franck, D. Pradelle e J.-F. Lavigne, Minuit, 1989.

HUSSERL, E. Expérience et jugement. recherches en vue d'une généalogie de la logique. Trad. D. Souche-Dagues. 3. ed. Paris: PUF, 2000. 
HUSSERL, E. Méditations cartésiennes: introduction à la phénoménologie. Trad. G. Peiffer et E. Lévinas. 9. ed. Paris: Vrin, 2001.

HUSSERL, E. La crise des sciences européennes et la phénoménologie transcendantale. Trad. G. Granel. Paris: Gallimard, 2004.

MERLEAU-PONTY, M. Phénoménologie de la perception. Paris: Gallimard, 1945.

MERLEAU-PONTY, M. Signes. Paris: Gallimard, 1960.

MERLEAU-PONTY, M. Le visible et l'invisible. Paris: Gallimard, 1964.

MERLEAU-PONTY, M. L'cil et l'esprit. Paris, Gallimard, 1985.

MERLEAU-PONTY, M. La nature. Paris: Seuil, 1995.

MERLEAU-PONTY, M. Le primat de la perception et ses conséquences philosophiques. Paris: Verdier, 1996.

MERLEAU-PONTY, M. Parcours deux (1951-1961). Lagrasse: Verdier, 2000.

MERLEAU-PONTY, M. Recherches sur l'usage littéraire du langage: cours au Collège de France: notes, 1953. Genève: MētisPresses, 2013.

SCHELLING, F. W. J. Les âges du monde. Trad. S. Jankélévitch. Paris: Aubier, 1949.

SILVA, C. A. F. A carnalidade da reflexão: ipseidade e alteridade em Merleau-Ponty. São Leopoldo: Nova Harmonia, 2009.

SILVA, C. A. F. A natureza primordial: Merleau-Ponty e o 'logos' do mundo estético. 2. ed. Cascavel: Edunioeste, 2019.

SILVA, C. A. F. “O retorno ao mundo da vida: Merleau-Ponty, leitor de Husserl”. Revista Filosófica de Coimbra, v. 21, p. 11-31, 2012.

RECEBIDO: $21 / 03 / 2019$

RECEIVED: 03/21/2019

APROVADO: 27/06/2019

APPROVED: 06/27/2019 